\title{
A inserção da educação ambiental crítica no currículo escolar: um estudo de caso da política curricular do Estado de São Paulo
}

\section{Daniele Cristina de Souza ${ }^{1}$ e Regina Helena Munhoz ${ }^{2}$}

1 Coordenadora e professora do Curso de Licenciatura em Educação do Campo na Universidade Federal do Triângulo Mineiro. Doutora em Educação para a Ciência pelo Programa de Pós-graduação de Pós-Graduação em Educação para a Ciência - UNESP Bau$\mathrm{ru} / \mathrm{SP}$.

2 Doutora em Educação para a Ciência e Matemática pela Universidade Estadual Paulista Júlio de Mesquita Filho Professor Titular da Universidade do Estado de Santa Catarina.

RESUMO: Uma das formas mais disseminadas para a inserção da Educação Ambiental (EA) na escola é pela transversalidade curricular, conforme proposto na década de 1990 pelos Parâmetros Curriculares Nacionais. Todavia, para além do discurso oficial, é importante identificar e compreender o que significa a inserção da educação ambiental via currículo, quais conteúdos e concepções sustentam as políticas e se estas contribuem para o desenvolvimento da Educação Ambiental Crítica. Neste sentido, o objetivo do trabalho é realizar uma discussão a partir de teorias de currículo e estabelecer um diálogo em direção a inserção da Educação Ambiental Crítica na escola. No âmbito da dimensão empírica será feito um estudo de caso da política curricular do estado de São Paulo considerando o documento oficial do currículo do ano de 2010. Sendo realizada especificamente uma análise do currículo do estado de São Paulo e suas relações com a EA, focando na compreensão de seu formato, seus códigos de seleção e organização curricular, assim como caracterizaremos o cenário político de sua implantação nas escolas públicas estaduais. A análise do documento que traz a política curricular para o Ensino Fundamental II e o Ensino Médio indicou imprecisões sobre os seus fundamentos teóricos. Enquanto fundamento teórico-pedagógicoidentificamos uma predominância da pedagogia relativista, de cunho construtivista. Por fim, pontuamos as contradições identificadas ao que se almeja para a construção da Educação Ambiental Crítica na escola.

Palavras-chave: fundamentos políticos-pedagógicos; ideias pedagógicas; currículo escolar

The insertion of the critical environmental education in the school curriculum: a case study of the curriculum policy in the São Paulo State

ABSTRACT: One of the most broadcasted ways regarding the insertion of the Environmental Education (EE) in school is related to the curriculum transverseness, according to what has been proposed in the 1990s by the National Curriculum Parameters. However, beyond the official discourse, it is important to identify and comprehend what the insertion of the environmental education via curriculum means, what content and which conceptions the policies support and if they contribute to the Critical Environmental Education development. This way, this study's objective is to promote a debate after the curriculum theories and to establish a dialogue towards the insertion of the Critical Environmental Education in school. The case study of the curriculum policy in 
the São Paulo state was made in the empirical dimension scope while taking into consideration the 2010 official curriculum document. A specific analysis of the São Paulo state curriculum and its relations with the EE was conducted while focusing the comprehension of its format, its selection codes and its curriculum organization, as well as the characterization of the political scenario of its implementation in the public state schools. The document analysis that brings the curriculum policy to the late stages of the elementary school and to the high school indicated imprecisions about its theoretical fundaments. Regarding the theoretical-pedagogical fundament we identified the predominance of the relativist pedagogy, which has a constructivist idea. Finally, we have pointed out the identified contractions in what it is aimed about the construction of the Critical Environmental Education in school.

Keywords: political-pedagogical fundaments; pedagogic ideas; school curriculum.

\section{INTRODUÇÃO}

Na primeira década do século XXI foram promovidos alguns estudos diagnósticos, visando a identificar como a Educação Ambiental (EA) se encontra inserida na Educação Básica. Estes estudos mostram uma crescente expansão dessa perspectiva nas escolas, em todos os estados brasileiros, podendo ser considerada como praticamente universalizada no ensino fundamental (VEIGA; AMORIM; BRANCO, 2005).

Apesar desta disseminação, como argumentam Tozoni-Reis et. alli (2013), as práticas existentes, em sua maioria, por seu caráter pontual e fragmentado, tendem a não serem feitas por meio da articulação com currículo enquanto expressão de conteúdos essenciais (SAVIANI, 2011) à formação dos estudantes. Predominam conceitos esvaziados e secundários desvinculados de uma perspectiva pedagógica consistente que favoreça uma formação crítica. Neste contexto, reconhecendo a necessidade de que a EA crítica seja inserida na escola via currículo escolar é que se propôs a realização do estudo trazido em Souza (2014), do qual é feito um recorte eapresentado neste trabalho.

Importante destacar que a perspectiva aqui assumida de Educação Ambiental busca ser coerente com a macrotendência crítica, mas há que se considerar que diversas são as propostas teóricas e educacionais relativas à $E A$, que atualmente configuram um campo social de disputas (LAYRARGUES; LIMA, 2011 e SOUZA; SALVI, 2012b).

Ao pensarmos a questão da inserção da EA crítica na educação básica pela via curricular enquanto conteúdos nucleares (SAVIANI, 2011), entendemos fundamental avançar nas análises para além de concepções e práticas e levar em consideração a realidade institucional da escola, assim como a política curricular vigente. A proposição da inserção de uma pedagogia crítica enquanto diretriz do trabalho pedagógico enfrenta a materialidade da ação pedagógica vigente que, por natureza histórica, é hegemonicamente não crítica (SAVIANI, 2011). Frente a esta concepção é que buscamos uma compreensão dos principais princípios da política curricular do Estado de São Paulo, buscando destacar algumas de suas distancias e/ou aproximações com a concepção de EA crítica.

A macro tendência Crítica em sua natureza parece ser a expressão político-pedagógica que mais se aproxima da radicalidade da crítica anticapitalista e da construção de um pro- 
jeto societário alternativo. Isto se dá pela forma com que concebe a questão ambiental associando-a ao conflito social, incluindo no debate a compreensão dos mecanismos da reprodução social e de que a relação entre o ser humano e a natureza é mediada por relações socioculturais e de classes historicamente construídas. Além disso, apresenta uma abordagem pedagógica contextualizadora e problematizadora das contradições do modelo de desenvolvimento e dos mecanismos de acumulação do Capital, luta contra as formas de autoritarismo, opressão, exploração e domínio, procura politizar o debate ambiental, articular as diversas dimensões da questão ambiental e sustentabilidade e buscar o enfrentamento político por meio da pedagogia do conflito para a superação da desigualdade e injustiça ambiental (LAYRARGUES, 2012).

A questão ambiental e a Educação são eminentemente políticas e, portanto, implicam na construção participativa radical dos sujeitos envolvidos, as qualidades e capacidades necessárias à ação transformadora responsável diante do ambiente em que vivemos. Dessa forma, a EA crítica tem que intensificar o enfrentamento do caráter autoritário, moralista, de transmissão mecânica de conteúdos pouco problematizadores e ingênua no que diz respeito ao conflito de interesses presentes nas sociedades modernas. A apropriação crítica de conhecimentos parte de uma concepção de ambiente mais complexa, que considera seu caráter social, histórico e dinâmico, superando dialeticamente a concepção biológica reducionista. Esta apropriação poderá garantir os espaços de construção e reelaboração de valores éticos para uma relação responsável dos sujeitos entre si e destes com o ambiente (TOZONI-REIS, 2006).

Neste sentido, a EA crítica exige uma abordagem histórica, ou seja, a tematização do ambiente pela redefinição do relacionamento entre os seres humanos, entre estes e as demais espécies e com o planeta, numa perspectiva autônoma e libertadora; exige o enfrentamento crítico da crise civilizatória, a difusão da discussão política da questão ambiental, uma abordagem radicalmente democrática da sustentabilidade - que supere o conceito hegemônico de desenvolvimento sustentável - a radicalização da participação social e do exercício democrático da cidadania, o incentivo ao debate interdisciplinar na produção da ciência, bem como uma problematização dos modos de produção e consumo, da ética, dos instrumentos técnicos e dos contextos sócio-históricos de sua produção; exige o enfrentamento da contradição entre os interesses públicos e privados, e uma ruptura de valores e práticas sociais contrárias aos interesses públicos, transformando-os em valores fundamentados na equidade social e na solidariedade humana (TOZONI-REIS, 2006). Estes aspectos precisam ser considerados nas proposições das políticas educacionais e refletidos nos currículos e práticas didático-pedagógicas nas escolas.

O currículo expressa uma determinada seleção cultural, reconhecida em determinado contexto histórico e social como necessária à formação dos alunos. Entretanto, é importante considerar que a organização curricular não é neutra e homogênea, nem se dá apenas em função do que é essencial nas diferentes ciências para ser ensinado na escola. A organização curricular procura responder determinada visão de sociedade, de cultura relevante, de relação entre escola e sociedade, de visões sobre os papéis a ser desempenhados pelos agentes pedagógicos e pelos materiais pedagógicos, assim como sobre quais os 
rituais pedagógicos desejados para o bom funcionamento da escola e para que sejam alcançadas as metas estabelecidas pelo Estado (CURY, 2000).

Neste sentido, o presente trabalho procura realizar uma análise dos princípios presentes no documento oficial deste currículo, buscando apontar as contradições que se colocam frente a uma perspectiva de Educação Ambiental Crítica.Os apontamentos que apresentamos são resultantes de análise que considera uma perspectiva de currículo enquanto práxis, isto é, que embora a principal fonte de dados seja documental procuramos localizalos em relação à materialidade pedagógica e aos aspectos políticos e ideológicos do processo educativo no período histórico em que nos debruçamos na análise (SAVIANI, 2011).

\section{A qUESTÃo CURRICULAR E O CONTEXTO dA POLÍTICA CURRICULAR do ESTADO de SÃo PAULO}

Partir de uma análise da questão curricular coloca em jogo uma diversidade de visões sobre o que é o currículo. Sem desconsiderar a produção realizada na área da teoria curricular, realizaremos uma reflexão principalmente estabelecendo um diálogo entre Sacristán (2000) que nos caracteriza diferentes dimensões do currículo, Apple (1986 e 1999) para destacar a relação currículo, ideologia e poder (política de seleção curricular) com a pedagogia histórico-crítica (SAVIANI, 2011).

Deste diálogo extraímos alguns elementos centrais para nossa análise: a função social da escola, a compreensão e a crítica política-ideológica sobre a seleção da cultural que é realizada para compor os currículos, a compreensão de que há a necessidade de delimitação de conhecimentosque componham o currículo enquanto conteúdos essenciais na/para a formação humana e que estes precisam ser traduzidos em saberes escolares, ação que o professor tem papel central enquanto mediador desse processo de apropriação, assim como a materialidade pedagógica que traz questões objetivas e subjetivas para o que realmente é trabalhado e apropriado em sala de aula.

O contexto histórico de nosso estudo é o momento em que a reforma curricular do estado de São Paulo estava se consolidando. O currículo foi proposto em 2008 e inserido no Programa "São Paulo faz a Escola", enquanto uma das estratégias para as 10 metas formuladas na política educacional da Secretaria Estadual de Educação de São Paulo (SEE-SP) para o período de 2007-2010, visando à melhoria da qualidade da educação (PALMA FILHO, 2010). De acordo com Okubo (2012, p.7-8), para se atingir as metas foram propostas pela SEE-SP dez ações:

1. Implantação do projeto Ler e Escrever;

2. Reorganização da progressão continuada;

3. Elaboração e divulgação das propostas curriculares da educação básica de São Paulo, com a indicação das expectativas de aprendizagem para todos os alunos em cada disciplina, série e ciclo do Ensino Fundamental e Médio;

4. Recuperação da aprendizagem: ciclos iniciais, 8a série e Ensino Médio;

5. Diversificação curricular do Ensino Médio;

6. Educação de jovens e adultos (Ensino Fundamental e Médio);

7. Ensino Fundamental de 9 anos e articulação com os municípios;

8. Sistemas de Avaliação; 
9. Gestão por resultados e política de incentivos;

10. Programa de incentivo à boa gestão da escola.

Estas ações foram avaliadas pelo IDESP (Índice de Desenvolvimento Educacional de São Paulo), estabelecido para o Estado e relativo à meta que cada escola deverá atingir (OKUBO, 2012). Ademais esta política curricular se articulou a outras políticas, em relação à formação e atuação dos professores, com o estabelecimento da política de bônus no salário, visando o controle do trabalho docente e o incentivo daqueles docentes que contribuíram com as notas das escolas no IDESP. Assim, gerou discussões em torno da abordagem autoritária que o estado impôs ao trabalho docente e na organização escolar, por meio das avaliações externas (ARCAS, 2010, OKUBO,2012), aspectos que aprofundamos em Souza (2014).

Neste contexto, identificou-se quea forma com que a política educacional do estado de São Paulo se configurou demonstra a tendência já criticada por Sacristán (2000), que enxerga o currículo como uma das principais entradas para a promoção de mudança na escola. Esta via é geralmente assumida, pois a alteração da estrutura do sistema de ensino não é tarefa fácil, valorizando-se então mecanismos mais sutis de intervenção. Como as alterações precisam considerar mudanças profundas nos conteúdos, nos procedimentos e nos contextos curriculares, consequentemente, é necessário serem articuladas à formação de professores. Há limitação nesta abordagem, uma vez que a alteração destes contextos curriculares precisa vir acompanhada do reconhecimento de que a prática escolar é institucionalizada e que, portanto, as mudanças também precisariam remover as condições que a mediatizam, atuando sobre todos os outros âmbitos práticos que condicionam e ultrapassam as práticas em sala de aula e delimitam as condições de trabalho.

\section{O DOCUMENTO ANALISADO E SEU VÍNCULO HISTÓRICO COM A POLÍTICA CURRICULAR DO ES- TADO DE SÃo PAULO}

Considerando o modelo proposto por Sacristán (2000), o recorte desta pesquisa é feito sobre o currículo prescrito - que se concretizou inicialmente como uma proposta curricular no ano de 2008 - sendo apresentado ao professor inicialmente com atividades de transição, preparando-o para a posterior inserção dos materiais didáticos de apoio, ou seja, dos Cadernos do Professor e do Aluno, bem como para a sua oficialização enquanto currículo, em 2010.

Dessa forma, neste artigo traremos principalmente a análise do documento oficial que contém os pressupostos e organização da política (SÃO PAULO, 2010). A análise considerando as relações entre esse documento, os materiais de apoio e a prática pedagógica de docentes estãona tese de doutorado(SOUZA, 2014).

O documento curricular possui uma apresentação inicial que afirma sustentar toda a proposta do currículo para o Ensino Fundamental II e o Ensino Médio, mas esta estrutura curricular está organizada em quatro áreas de conhecimento, as quais possuem algumas especificidades, sendo estas: Ciências Humanas e suas Tecnologias; Ciências da Natureza e 
suas Tecnologias; Linguagens, Códigos e suas Tecnologias; Matemática e suas Tecnologias ${ }^{1}$. Cada área de conhecimento possui uma caracterização em relação aos seus conteúdos, relevância social e especificidade nos diferentes níveis de ensino, assim como cada disciplina recebe uma apresentação, trazendo outros elementos ou interpretações dos seus princípios gerais. No entanto, o currículo procura indicar que estas diferentes áreas estão relacionadas e se comunicam no projeto político pedagógico da escola.

A título de exemplo da organização curricular apresenta nessa política, cita-se a disciplina de Ciências. Neste currículo há um breve resgate da história do ensino de Ciências e das propostas curriculares de São Paulo; tomando a reforma curricular dos anos de 1980, considera que naquela década o currículo do estado estava centrado no ambiente como tema gerador, o que influenciou os PCNs e, de certa forma, foi mantido no currículo de 2010. Os conteúdos do currículo vêm apresentados por disciplinas, série/ano e por bimestre, englobando não só os conhecimentos específicos, mas as habilidades que precisam ser desenvolvidas pelo aluno em cada bimestre. Há uma breve caracterização de cada disciplina no âmbito escolar e argumentações sobre a organização dos conteúdos básicos, assim como sobre a metodologia de ensino e aprendizagem sugerida. O currículo de Ciências está sustentado em quatro eixos temáticos: Vida e Ambiente; Ciência e Tecnologia; Ser humano e Saúde; Terra e Universo. Cada eixo é caracterizado por temas que podem se repetir de diferentes formas nas diferentes séries/anos.

O Currículo em questão vem acompanhado de alguns documentos de orientação e de documentos denominados de gestão do currículo na escola; o Caderno do Gestor é dirigido aos professores coordenadores, aos diretores, aos professores Coordenadores das Oficinas Pedagógicas ( PCOPs $^{2}$ ) e aos supervisores, e visa auxiliar o gestor na implementação e orientação curricular na escola, reforçando aspectos sobre a formação continuada dos professores da escola. Este currículo seria concretizado nas escolas a partir dos materiais de apoio ao professor e ao aluno, representados pelo Caderno do aluno e Caderno do professor, no nível Fundamental II e no Ensino Médio.

Os Cadernos do Professor e os do Aluno são apostilas nas quais constam os conteúdos a serem trabalhados em sala de aula. A estrutura dos materiais traz diferentes Situações de Aprendizagem (SA) que buscam contemplar a organização do conteúdo desde os objetivos e finalidades propostos, até o tempo previsto de aulas necessário; também trazem os textos para leitura, diferentes atividades e até a proposição de recuperação de conhecimentos pelos alunos, além de sugestões de links, vídeos e literaturas para pesquisas sobre os assuntos abordados.

Duran (2012) apresentou uma caracterização semelhante presente na política curricular da década de 1970, em plena ditadura militar. Naquele período o currículo era organizado a partir de Guias Curriculares direcionadores, que visavam orientar a elaboração dos planejamentos escolares para cada disciplina. De acordo com o autor, a partir destes guias a

\footnotetext{
${ }^{1}$ Currículo disponível em: <http://www.rededosaber.sp.gov.br/portais/MATERIALDAESCOLA/CURR\%C3\%8DCU LO/ta bid/1541/Default.asp>

2 Denominados, a partir do ano de 2012, como PCNP (Professores Coordenadores do Núcleo Pedagógico).
} 
CENP organizou os chamados "Subsídios Curriculares" que "discutiam, passo a passo, o desenvolvimento dos conteúdos diários. Os professores tinham ali, portanto, uma sequência dos conteúdos e das maneiras como desenvolveriam o seu trabalho, no dia a dia" (p.18). Além disso, os guias estavam diretamente relacionados à definição dos conteúdos presentes nos materiais didáticos, o que foi fortemente utilizado pelas editoras para a configuração dos livros didáticos que chegavam às escolas.

A década de 1970 foi propícia para a concepção pedagógica tecnicista que advogava uma "reordenação do processo educativo de maneira que o torne objetivo e operacional" (p.381), sustentada nos princípios de racionalidade, eficiência e produtividade. Com isso as escolas passaram por uma reorganização pautada em um processo de burocratização, visando indicativos para os diferentes profissionais no desempenho de tarefas especificas no cenário de ampla fragmentação pedagógica que então se configurava. Essa concepção contribuiu para o aumento do caos no campo educativo, promovendo grandes níveis de descontinuidade, heterogeneidade e fragmentação que praticamente inviabilizaram o trabalho pedagógico (SAVIANI, 2010).

A década de 1980 representou um momento de mobilização e questionamento da política anterior e outra proposta foi configurada, embora esta não tenha tido o impacto esperado. Naquele período, caracterizado como momento de redemocratização do país, houve um intenso debate em torno do currículo que seria desenvolvido na escola. Este movimento envolveu não só o segmento estatal da CENP, mas também as universidades, os especialistas e os professores. O debate não foi a partir do conteúdo em si, como na década anterior, mas dos caminhos oferecidos pela escola na sociedade que se configurava, o que levava a implicações para os conteúdos e perspectivas pedagógicas, influenciado pelas teorias pedagógicas críticas (SAVIANI, 2010).

\section{UMA ANÁlise do dOCUMENTO do CuRRículo do ESTAdo de SÃo PAUlO}

Nossos resultados da análise serão apresentados mediante destaque de algumas categorias que extraímos ao realizar uma leitura crítica do documento (SÃO PAULO, 2010) a partir do materialismo histórico dialético, fundamento da Pedagogia Histórico Crítica (SAVIANI, 2011), desprendendo algumas dimensões no que tange a educação escolar destacadas na sequência.

\section{A função social da escola e a marginalidade social}

O documento oficial propõeuma educação de qualidade frente aos desafios da sociedade contemporânea; os desafios sociais sãocaracterizados no documentocomo composto por outro tipo de desigualdade e exclusão sociais, referentes ao uso/acesso ou não das tecnologias de comunicação, as quais são mediadoras do acesso ao conhecimento e à cultura. Assim, no documento afirma-se que a qualidade da educação é expressa pelas formas de socialização dos conhecimentos e as competências desenvolvidas na escola, pois fundamentais para a participação dos indivíduos no seu grupo social e, mesmo, para que "eles 
tomem parte em processos de crítica e renovação" (SÃO PAULO, 2010, p. 9). Em contraposição, a noção de qualidade de ensino é questionada por Ribeiro (2008), por apresentar múltiplos e ambíguos significados. No caso do sentido predominante na proposta, o autor entende que a qualidade de ensino está associada à melhoria dos índices obtidos pelos alunos nas avaliações externas estaduais (como o SARESP) e federais (como o ENEM), o que é questionável do ponto de vista qualitativo e enquanto finalidade educativa.

$\mathrm{Na}$ apresentação geral do documento, que se aplica a todas as disciplinas, reconhece-se o variado perfil socioeconômico dos alunos e suas diferentes experiências, isto como resultante da universalização da escola básica. Neste processo são valorizados: o "desenvolvimento do pensamento autônomo" do aluno e o "aprender a ser livre e, concomitantemente, respeitar as diferenças e as regras de convivência. (...) Apenas uma educação de qualidade para todos pode evitar que essas diferenças se constituam em mais um fator de exclusão" (p.9), onde "apropriar-se desses conhecimentos pode ser fator de ampliação das liberdades, ao passo que sua não apropriação pode significar mais um fator de exclusão" (SÃO PAULO, 2010, p.10). Este discurso de se reconhecer as diferenças e aceitá-las, bem como da educação evitar a exclusão tecnológica e cultural está bastante presente na defesa da educação proposta pelo currículo.

A ênfase na exclusão tecnológica, em nossa concepção secundariza a desigualdade social de maneira mais global, pois não existe a indicação de argumentos voltados para a busca ou para a garantia da equidade social. Neste sentido, aanálise indica influências de pressupostos da teoria educacional não crítica argumentada por Saviani (1981). Esta aproximação é feita, principalmente, a partir da caracterização trazida pelo currículo sobre a relação ensino, aprendizagem e conteúdos, uma vez que são desconsideradas as condições materiais que mediatizam o processo educativo. Estas condições são até citadas, tais como a caracterização da diversidade socioeconômica dos alunos e da existência do fenômeno da exclusão (que aparece de forma muito abstrata), mas tudo isto é praticamente naturalizado quando há predominância de afirmações sobre a necessidade de se aprender a conviver com as diferenças ou mesmo que a escola deve contribuir para que a exclusão tecnológica não ocorra, o que se aproxima de uma visão multiculturalista liberal ou humanista (SILVA, 2010).

De acordo com o documento curricular, cabe à educação escolar formar sujeitos capazes de lidar com a sociedade do conhecimento e responder a sua dinâmica e demandas. "Preparar os indivíduos para o diálogo constante com a produção cultural, num tempo que não se caracteriza pela permanência, mas pela constante mudança - quando o inusitado, o incerto e o urgente constituem a regra -, é um desafio contemporâneo para a educação escolar" (SÃO PAULO, 2010, p.10). Também se pode ler:

Este documento apresenta os princípios orientadores do currículo para uma escola capaz de promover as competências indispensáveis ao enfrentamento dos desafios sociais, culturais e profissionais do mundo contemporâneo. Contempla algumas das principais características da sociedade do conhecimento e das pressões que a contemporaneidade exerce sobre os jovens cidadãos, propondo princípios orientadores para a prática educativa, a fim de que as escolas possam preparar seus alunos para esse novo tempo (SÃO PAULO, 2010, p.7, grifo nosso). 
[...] o currículo se compromete em formar crianças e jovens para que se tornem adultos preparados para exercer suas responsabilidades (trabalho, família, autonomia, etc.) e para atuar em uma sociedade que depende deles. (idem, p.12)

A noção de inserção dos alunos no mundo produtivo é repetidamente colocada no texto do currículo, como pode ser visto no momento em que se caracteriza o papel da escola: de promover aprendizagens que viabilizem o acesso dos alunos a "uma real oportunidade de inserção produtiva e solidária no mundo" ou ainda, de que o desenvolvimento de diferentes conhecimentos e competências é "essencial para a inserção cidadã nas dimensões sociais e produtivas" (p.9). Assim, podemos aproximar esta caracterização à abordagem que Saviani (1981) em que a escola é compreendida como um espaço para equalização social. Nas palavras deste autor:

A educação, enquanto fator de equalização social será, pois, um instrumento de correção da marginalidade na medida em que cumprir a função de ajustar, de adaptar os indivíduos à sociedade, incutindo neles o sentimento de aceitação dos demais e pelos demais. Portanto, a educação será um instrumento de correção da marginalidade na medida em que contribuir para a constituição de uma sociedade cujos membros, não importam as diferenças de quaisquer tipos, se aceitem mutuamente e se respeitem na sua individualidade específica (SAVIANI, 1981, p.9).

Esta noção de individualidade é resgatada no currículo a partir das ideias do desenvolvimento da autonomia e liberdade do aluno; estas finalidades formativas para a educação escolar serão viabilizadas pela responsabilização dos alunos pelo seu processo de aprendizagem ("aprender na escola é o 'ofício do aluno'”), pelo direcionamento do professor para o desenvolvimento do aprender a aprender no aluno e para desenvolvimento de diferentes habilidades e competências. Ao mesmo tempo, também é trazido o resgate da cooperação e da solidariedade como viabilizadores desta educação, ou seja, a autonomia (lê-se individual), a liberdade e a identidade do aluno se darão na coletividade; este aspecto coletivo se expressa ao longo da caracterização do currículo como uma dualidade, pois há sempre uma centralidade no sujeito aluno, o que é característico da pedagogia do aprender a aprender.

Newton Duarte é um pesquisador que vem realizando estudos e críticas sobre o que denomina pedagogia do aprender a aprender; suas críticas permitem identificar coerência com o que obtivemos de caracterização deste documento oficial. De acordo com Duarte (2008a), é importante o aluno desenvolver uma autonomia intelectual, capacidades e iniciativa de buscar por si mesmo os conhecimentos, mas o autor questiona o posicionamento valorativo que esta perspectiva assume quando prioriza, do ponto de vista educativo e social, o que o sujeito aprende por si mesmo em detrimento daqueles conhecimentos que alguém Ihe transmite; quando considera que o método de aprendizagem é mais importante do que o próprio conhecimento já produzido socialmente; quando admite que a atividade dos alunos, para ser educativa, deverá ser impulsionada e dirigida pelos interesses destes, assumindo que a educação deve possibilitar que os indivíduos acompanhem a sociedade que se encontra em um processo acelerado de mudança, na qual os conhecimentos 
- modificados constantemente - são considerados cada vez mais provisórios.

Sobre este último elemento valorativo, Duarte (2008a) argumenta que tal perspectiva pedagógica se coadunada com uma concepção de educação voltada para uma formação de indivíduos que se adaptem à sociedade regida pelo capital, sendo, portanto, uma pedagogia para a adaptação. A interpretação do autor ganha sentido em um trecho do currículo aqui analisado que, contido no princípio de articulação com o mundo do trabalho, defende o desenvolvimento de competências e habilidades mais gerais, válidas para todos os contextos e demandas do mundo de trabalho, considerando, portanto a sua dinamicidade:

A medida que a tecnologia vai substituindo os trabalhadores por autômatos na linha de montagem e nas tarefas de rotina, as competências para trabalhar em ilhas de produção, associar concepção e execução, resolver problemas e tomar decisões tornam-se mais importantes do que conhecimentos e habilidades voltados para postos específicos de trabalho (SÃO PAULO, 2010, p. 23).

A partir destes princípios, encontramos uma concepção de sociedade representada pela velocidade com que são produzidas e divulgadas novas informações; uma sociedade diversa e dinâmica, permeada de ciência e tecnologia; uma educação centrada no mundo do trabalho, entendendo que o processo educativo visa formar competências e habilidades nos alunos para que estes possam participar e se integrar àquele. $E$, embora na apresentação do currículo seja sugerida uma formação que prepare o aluno para o "enfrentamento dos desafios sociais, culturais e profissionais do mundo contemporâneo" (SÃO PAULO, 2010, p.7), o documento traz também assertivas que permitem que este mundo contemporâneo seja caracterizado pela noção de sociedade do conhecimento, portanto, se distanciando do questionamento da sociedade capitalista necessário e fundante para a Educação Ambiental Crítica.

Não há no documento qualquer indicativo de que a formação deva ser encaminhada para a superação de situações ou para a transformação social, o que é fundante para a EA crítica. A caracterização destacada aqui se coaduna com os apontamentos de análises que realizam críticas a obras de autores que defendem a pedagogia da competência, a exemplo daquelas análises realizadas por Duarte (2008a) e Facci (2004), cuja síntese é representada no fragmento abaixo.

Parece que para esses teóricos [da pedagogia da competência] é a transmissão de conhecimentos que precisa ser substituída, na escola, pelo desenvolvimento de competências. A questão que fica é: bastam noções vagas, conhecimentos fluídos - espontâneos, fáceis, naturais - para saber fazer cálculos, analisar fatos e situações, ser um leitor e escritor proficiente? Isso poderá ser suficiente se a finalidade consistir em reproduzir a prática social estabelecida. Porém, se tal formação pretende formar o profissional comprometido com a crítica ao modo de vida dominante isto contribui muito pouco (FACCl, 2004, p. 39-40).

Ademais, na sequência apontamos outros aspectos que se contrapõem às conclusões trazidas no trabalho de Santos e Frenedozo (2013). Os autores identificaram uma perspectiva de Educação Ambiental Crítico Transformadora no Documento do Currículo oficial e nos Cadernos de apoio de Biologia do estado de São Paulo, os quais passaram por atualiza- 
ção no ano de 2012 e 2013, respectivamente. Portanto, a política curricular recebeu atualizações em relação ao documento aqui analisado, aparentemente modificando-se um pouco a estrutura do currículo prescrito. Os mesmos autores apontam que o documento do currículo oficial foi mais consistente em relação a perspectiva de educação ambiental crítica do que o observado em relação aos cadernos de apoio de biologia (estes que são os materiais efetivamente utilizados em sala de aula e trazem as situações de aprendizagem). Essa contradição entre os resultados apresentados em relação ao estudo de Santos e Frenedozo (2013) nos documentos atualizados merece aprofundamento futuro, pois há diferenças de enfoque metodológico entre os estudos, visto que aqueles autores não fizeram análise dos fundamentos político-pedagógicos.

A relação entre o conhecimento, o professor, o aluno, a prática social e a função social da escola

Sobre esta dimensão faremos maiores apontamentos a partir do que é apresentado na área de Ciências da Natureza e suas Tecnologias e destaque dos seis princípios gerais da política curricular.

De acordo com o documento (SÃO PAULO, 2010), esta área visa contemplar a forte presença das Ciências da Natureza em nossa sociedade, bem como a relação destas com a tecnologia e as influências desta última, exercidas nos diferentes setores, tais como na saúde, agricultura, construção civil e ambiente etc. Além disso, é ressaltada a sua dimensão filosófica como possibilidade de permitir a interpretação de eventos naturais, assim como de monitorar e controlar o desenvolvimento científico e tecnológico, ao investigar os impactos da intervenção humana na biosfera e, eventualmente, estabelecer seus limites, correspondendo a uma dimensão ética. A dimensão das ciências naturais no sentido de permitir uma visão do mundo natural é ressaltada, o que também ocorre com a dimensão estética presente no conhecimento e na investigação científica. Neste contexto, os conteúdos de aprendizagem são o domínio da linguagem científica e a compreensão de situações e fenômenos cotidianos que envolvem a ciência e a tecnologia em nossa sociedade (SÃO PAULO, 2010).

A presença das diferentes disciplinas das ciências naturais em uma só área procura possibilitar que tais conhecimentos sejam trabalhados de forma articulada, assim como com diferentes entonações, dependendo do nível de ensino. No Ensino Fundamental, as diferentes ciências estão integradas em uma única disciplina; no 6ㅇ e 7음 anos estão focadas na realidade imediata do aluno, suas vivências e percepções, enquanto nos 80 e 9 o anos há um deslocamento para temas mais abrangentes e suas interpretações. Já no Ensino Médio trata das especificidades das disciplinas Biologia, Física e Química, com aprofundamentos embora sem exagerar em seu caráter propedêutico - pois sugere a delimitação de competências relacionadas aos conhecimentos científicos e aos contextos reais (SÃO PAULO, 2010).

$\mathrm{Na}$ apresentação dos pressupostos do currículo há forte ênfase na delimitação dos conteúdos do ensino a partir da ideia de que os conteúdos científicos estão distanciados da 
vida real do aluno, sendo necessário que se aproximem e se refiram aos contextos reais dos estudantes. Nesta argumentação encontramos uma desvalorização do ensino voltado para um aprofundamento em torno dos conhecimentos científicos, como se isso fosse uma barreira para se compreender a realidade, desconsiderando a questão do desenvolvimento do pensamento superior. Este aspecto, de acordo com Duarte (2008b), é coerente com uma perspectiva curricular relativista e pragmática, no sentido de que os conteúdos a serem ensinados englobam aqueles significativos e relevantes para os alunos e que tenham alguma utilidade prática, entendendo o conhecimento como um instrumento para a resolução de problemas, o que pode acarretar a supervalorização dos conhecimentos tácitos e circunstanciais. Ainda, de acordo com o autor, esta perspectiva passa a exigir do professor outra função, pois este deixa de ser o mediador entre o aluno e o patrimônio cultural da humanidade para ser um organizador de atividades que promovam a negociação de significados construídos pelos alunos no cotidiano, no seu desenvolvimento de habilidades e competências.

Sobre esta concepção trazida no currículo é possível de ser aprofundada com a análise dos princípios gerais no documento, sendo eles: a) uma escola que também aprende; b) o Currículo como espaço de cultura; c) As competências como referência; d) Prioridade para a competência de leitura e da escrita; e) Articulação das competências para aprender; e f) Articulação com o mundo do trabalho. Estes são caracterizados na sequência.

a) Uma escola que também aprende: a escola precisa assumir a concepção de um constante aprender a ensinar e não somente ensinar, não se tomando como a única detentora do conhecimento. A escola, a bem da verdade, vem representando os professores e gestores que precisam entender o espaço escolar como formativos para si próprios. Neste processo se valoriza a participação e a coletividade, a problematização e significação dos conhecimentos sobre a prática. Os gestores desempenham importante papel na formação dos professores, havendo neste tópico a cobrança da responsabilidade dos professores e gestores para o funcionamento escolar (SÃO PAULO, 2010).

De acordo com Contreras (2012), essa ideia de escola como "organização que aprende" é um lema atual que vem ganhando força nas reformas educacionais. Tal ideia é trazida do mundo empresarial, que a compreende como "uma estratégia de adaptação às condições de produção flexível e consumo acelerado e mutante da sociedade pós-moderna" (p.257). No âmbito escolar, esta se enquadra na compreensão de que não existe uma solução definitiva para os problemas que atingem a educação, uma vez que estes mudam temporal e espacialmente, portanto, as soluções precisam ser vistas como provisórias e adequadas a cada caso particular ou escola. Neste contexto de mutabilidade, as "organizações educativas devem aprender a se adaptar e a encontrar suas próprias estratégias de ação" (p.257). Assim, embora aparentemente tal lema permita aos professores desenvolverem por si mesmos os currículos e direcionarem as estratégias de ensino em função das demandas do contexto, trata-se de uma forma de inserir valores empresariais e economicistas na escola, um espaço que deveria ser regido por uma ética educativa e não empresarial.

Esta noção de organização - que aprende e encontra os melhores caminhos para a ação e que pode inicialmente parecer democrática e autônoma é, de certa forma, assumida pela 
proposta, mas identificamos contradições: ao mesmo tempo em que responsabiliza os professores e gestores pelo seu próprio processo de aprendizagem, e incentiva um processo de planejamento e ação coletivo e compartilhado, delimita a priori a forma e o conteúdo desta aprendizagem e ações (pelo Caderno do Gestor, Cadernos do professor e aluno), assim, o trabalho não é feito, na realidade, de forma coletiva e contextual, mas de forma burocrática e técnica.

Além disso, no que se refere ao professor apenas aponta a responsabilidade deste pela sua formação, alertando que esta deve se dar continuamente na escola, porém, até que ponto o professor recebe subsídios para que tal formação ocorra? Qual é a verdadeira formação fornecida/desejada para estes professores? Neste contexto, a responsabilidade formativa é transferida ao gestor: "Os gestores, como agentes formadores, devem por em prática com os professores tudo aquilo que recomendam a eles que apliquem com seus alunos" (SÃO PAULO, 2010, p.11). Assim, parte-se da ideia de que os princípios que são utilizados na formação dos alunos sejam os mesmos utilizados na formação dos professores.

As normativas da Secretaria de Educação para a formação de professores estiveram centradas em ações para a implantação deste currículo e de seus pressupostos (SOUZA, 2014). Mesmo que aparentemente focado em uma preocupação com a formação dos professores, o princípio está centrado na indicação da necessária coerência entre a teoria e a prática do professor, de acordo com o que é trazido no currículo prescrito. "Observar que as regras da boa pedagogia também se aplicam àqueles que estão aprendendo a ensinar é uma das chaves para o sucesso das lideranças escolares" (SÃO PAULO, 2010, p.11). Nós nos perguntamos: o que está sendo chamado de "boa pedagogia"? A partir da caracterização dos princípios do currículo, certamente poderemos dizer algo sobre essa pedagogia defendida, já que ela não é explicitamente definida e nem são indicados referenciais que permitam um aprofundamento teórico sobre o que é considerado como princípios. Esta "boa pedagogia" expressa um perfil profissional que, teoricamente, o professor precisa atingir para que efetue um bom trabalho e seja obtido um bom ensino, na visão desta política curricular.

b) O Currículo como espaço de Cultura: indica a necessidade de superação da dicotomia atrelada à concepção de que cultura representa algo local, pitoresco e folclórico, enquanto os conhecimentos são associados a algo praticamente inatingível. Como encontramos no documento: "esta dicotomia não cabe em nossos tempos: a informação está disponível a qualquer instante, em tempo real, ao toque de um dedo, e o conhecimento constitui ferramenta para articular teoria e prática, o global e o local, o abstrato e seu contexto físico" (SÃO PAULO, 2010, p.11). Como é possível notar, as informações e conhecimentos são tratados praticamente como sinônimos, desconsiderando as desigualdades de oportunidade de acesso à informação, características das diferentes regiões do estado de São Paulo e de suas respectivas escolas. Esta noção de que o acesso ao conhecimento se encontra plenamente democratizado é igualmente apontada por Duarte (2008a) como sendo uma das ilusões que a ideia de sociedade do conhecimento procura disseminar.

O currículo é definido como "expressão do que existe na cultura científica, artística e 
humanista transposto para uma situação de aprendizagem e ensino" e há o entendimento de que "todas as atividades da escola são curriculares; caso contrário, não são justificáveis no contexto escolar" (SÃO PAULO, 2010, p.11). Extraímos que a noção de atividades extraclasse como extracurriculares é diluída ao ser assumida também como curriculares e, de acordo com o documento, estas só devem ser realizadas quando o entendimento for pautado na articulação entre conhecimento e cultura, uma vez que permite a conexão do currículo à vida.

No entanto, qual é a relação que se está indicando entre o conhecimento e a cultura? Qual a relação com a vida? Qual a concepção de cultura? É difícil extrair uma caracterização sobre estes aspectos a partir do que está contido em apenas quatro parágrafos deste princípio, mas é enfatizado o aspecto metodológico, principalmente no que tange à ideia do currículo ampliar, localizar e contextualizar os conhecimentos acumulados pela humanidade. Isto é, os pressupostos teóricos não se apresentam muito claros e delineados, mas o como colocá-los em ação parece ser a principal preocupação na descrição deste princípio. Neste processo se valoriza o aprender a aprender e se coloca como papel do professor não só o de suprir os alunos de saberes, mas de ser "parceiro nos fazeres culturais" (SÃO PAULO, 2010, p.11), ou seja, a escola não é apenas o espaço onde se ensina a cultura, mas também onde esta deve se concretizar.

Outra ideia que merece discussão é a seguinte: "Todas as atividades da escola são curriculares; caso contrário, não são justificáveis no contexto escolar" (SÃO PAULO, 2010, p.11). Esta afirmação pode ser discutida a partir de Saviani (2011), quando o autor define as especificidades da educação, sobretudo daquela realizada na escola, pois se tudo que se fizer na escola for considerado currículo, se apaga o que é curricular do extracurricular e, assim,

[...] abre-se caminho para toda sorte de tergiversações, inversões e confusões que terminam por descaracterizar o trabalho escolar. Com isso facilmente o secundário pode tomar lugar daquilo que é principal, deslocando-se, em consequência, para o âmbito do acessório aquelas atividades que constituem a razão da escola (SAVIANI, 2011, p.15).

Há uma dificuldade de entendimento sobre a concepção de currículo no documento curricular, pois ao mesmo tempo em que o currículo é definido como expressão da cultura científica, artística e humanística em um contexto de ensino, o que pode trazer a ideia de ser constituído por saberes sistematizados, também considera que tudo que for realizado na escola é currículo. Talvez haja uma tentativa no sentido de que o currículo venha a contemplar a questão apontada por Saviani (2011), na década de 1980, sobre a especificidade de a educação escolar estar voltada à transmissão dos saberes sistematizados. No entanto, o documento ressalta a indicação de que estes sejam contextualizados nos âmbitos da vida e da realidade do aluno, a partir do que chama de articulação entre conhecimento e cultura, mas, o que implica esta contextualização?

Um dos entendimentos que construímos é o de que há a preocupação com uma relação entre as culturas científica, artística e humanística com a cultura popular ou saberes cotidianos. Assim, infere-se que uma atividade extraclasse poderia ser o espaço de aplicação/contextualização de um conhecimento específico e, portanto, seria curricular - isto é, 
estaria vinculada aos conteúdos que o currículo oficial propõe. Como encontramos no documento:

Se não rompermos essa dissociação entre cultura e conhecimento não conectaremos o currículo à vida - e seguiremos alojando na escola uma miríade de atividades "culturais" que mais dispersam e confundem do que promovem aprendizagens curriculares relevantes para os alunos (SÃO PAULO, 2010, p.11).

Esta visão de aplicação do conhecimento vinculado ao contexto é necessária e relevante, mas pensamos que precisaria ser mais discutida no documento. Na concepção crítica de educação a realidade imediata é tomada como ponto de partida e não como ponto de chegada em si mesmo; não se pode limitar o ensino assumindo a abordagem e a discussão de apenas questões que façam parte da realidade imediata do aluno, pois isso limitaria a formação de sujeitos capazes de uma mais ampla interpretação da realidade, o que inviabiliza a formação de uma consciência crítica. Assim, concordamos com Saviani (2011) com relação à sua crítica à afirmação "de que tudo que for realizado na escola é currículo" por entendermos que isto se expressa como uma armadilha que pode fomentar, ainda mais, o esvaziamento dos conteúdos e a indefinição do que é relevante ser ensinado e aprendido.

Se o currículo é entendido como "expressão do que existe na cultura científica, artística e humanista transposto para uma situação de aprendizagem e ensino" (SÃO PAULO, 2010, p.11), qual cultura está sendo referida? Qual é a sua delimitação, visto que, segundo Sacristán (2000, p. 61), "não existe campo ou aspecto cultural que não esteja submetido a valorizações sociais diversas"? Assim, é importante destacarmos a não neutralidade deste currículo e buscarmos compreender seus interesses e seus códigos de organização ou formato.

Conforme Apple (1982) teoriza, o currículo é um espaço de inculcação ideológica que legitima e reproduz o que é hegemônico. Para o autor, neste projeto cultural são selecionados e transmitidos determinados conhecimentos que favorecem a reprodução da organização social hegemônica, caracterizada pela estratificação social e a opressão, uma vez que geralmente é o mesmo grupo que centraliza sua organização. Apple (1982) ainda afirma existir uma distribuição desigual da cultura entre as diferentes classes sociais e econômicas, grupos profissionais, faixa etária e grupos com diferentes poderes, havendo uma relação entre a distribuição cultural e a distribuição do controle do poder econômico e político, ou seja, a relação conhecimento e poder.

Como afirma Apple (1999), "a educação está intimamente ligada à política da cultura" (p.59) que representa as práticas delimitantes dos conteúdos a serem ensinados na escola; no entanto não somente ocorre a delimitação do conteúdo, mas também a forma como este se organiza, quem poderá transmiti-lo, o que é considerado como aprendizagem e até quem pode perguntar e responder a todas essas questões. Tudo isso está relacionado com a maneira como o domínio e a subordinação são reproduzidos e alterados na sociedade. Assim, o currículo não é apenas um conjunto neutro de conhecimentos que são desenvolvidos em sala de aula, mas é parte de uma tradição seletiva, cujo resultado expressa a visão de um grupo do que seja conhecimento relevante. "Sempre existe, pois uma política 
do conhecimento oficial, uma política que exprime o conflito em torno daquilo que alguns veem simplesmente como descrições neutras do mundo e outros, como concepções de elite que privilegiam determinados grupos e marginalizam outros" (APPLE, 1999, p.60).

Em suma, faz parte da preocupação da teoria crítica sobre o currículo compreender que a seleção e organização curricular levam a opções sociais e ideológicas conscientes e inconscientes, o que precisa ser relacionado com a estrutura institucional e interativa nas escolas e, posteriormente, com o contexto mais amplo das estruturas institucionais que envolvem as salas de aula (APPLE, 1982), as mediações, contradições e ambiguidades dos processos de reprodução social e cultural, em que compreende-se que a questão de que a reprodução social não é um processo tranquilo e garantido (APPLE, 1999) e que, portanto, as contradições da realidade podem favorecer uma práxis distinta da colocada pelas políticas oficiais.

Avançando no documento, após a explicitação deste princípio, em outro momento esta noção de cultura é percebida quando da caracterização das áreas de conhecimento que organizam os conteúdos, como é o caso das Ciências da Natureza e Tecnologia, no âmbito do conhecimento e aprendizagem do aluno. Esta área é citada em suas dimensões estéticas, filosóficas e éticas, fornecendo uma visão de mundo cuja centralidade está na vida do aluno, viabilizando a compreensão de sua realidade e tomada de decisões, com destaque para as implicações científicas e tecnológicas na sociedade. Há indicações da necessidade de variação do aprofundamento das questões a serem trabalhadas, dependendo do nível de ensino. Assim, no ensino fundamental ressalta-se a finalidade da educação possibilitar a identificação e qualificação de diferentes tecnologias presentes em diferentes contextos do mundo produtivo: nas comunicações, saúde, nos setores de bens de consumo e no monitoramento ambiental etc., envolvendo também questões globais como a defesa da biodiversidade ou o comprometimento dos mananciais de água. Considerando temáticas semelhantes, no Ensino Médio se compreende que as ciências são provedoras de linguagens, instrumentos e critérios para os alunos lidarem com tais questões, sendo "recursos de expressão, instrumento de julgamento, tomada de posição ou resolução de problemas em contextos reais" (SÃO PAULO, 2010, p.28).

Finalizando, nosso olhar para o princípio "o Currículo como espaço de Cultura" reconhecemos que sua forma de apresentação parece um tanto difusa, pois coloca rapidamente vários elementos, sem que haja uma devida explicação e referência, podendo confundir seu entendimento; citam-se aspectos como a concepção de cultura, a concepção de currículo, a relação informação/conhecimento/saberes/rede de informação e o sentido da aprendizagem, os papéis do professor e do aluno, o papel da escola, a relação currículo e vida, o projeto pedagógico da escola e o que denominam de cidadania cultural, aspectos que mereceriam um maior aprofundamento teórico para a sua compreensão.

c) As competências como referência: os conhecimentos devem estar articulados com o desenvolvimento de competências e habilidades dos alunos. Competências "caracterizam modos de ser, de raciocinar e de interagir que podem ser depreendidos das ações e das tomadas de decisão em contextos de problemas, de tarefas ou de atividades" (p.12). 0 desenvolvimento destas competências deve vir acompanhado da consideração das especi- 
ficidades dos alunos (suas ações e pensamentos), do professor (suas características pessoais e profissionais) e dos conteúdos e metodologias de ensino (SÃO PAULO, 2010).

Esta centralidade nas competências se caracteriza pela mudança de foco da educação escolar do ensino para a aprendizagem, sustentando-se nas proposições da LDB n9394/96, nas Diretrizes Curriculares Nacionais (DCNs) e nos PCNs. Não há indicação do que é preciso ensinar, mas apenas do que o aluno precisa aprender. Tal proposta é justificada pelo documento curricular por contemplar uma educação mais democrática com relação às demandas heterogêneas que a universalização do ensino vem trazendo, enfatizando as competências mínimas que todos têm o direito de construir, considerando-se a diversidade. No entanto, esta exige mudanças metodológicas do professor e um trabalho coletivo na escola (SÃO PAULO, 2010).

Ribeiro (2008) problematiza o princípio do estabelecimento de um currículo mínimo, em que historicamente, no Brasil passou a se constituir na prática um currículo único, pois embora alguns professores trabalhem outras atividades e conteúdos, além dos que são trazidos no currículo, geralmente o que ocorre é uma limitação ao mesmo. Afinal, as avaliações externas serão baseadas nestes conteúdos, portanto, serão cobrados pelos coordenadores e gestores.

Cabe aqui uma reflexão a respeito: Qual é o sentido do "democrático" defendido neste currículo? Sobre esta questão, outros elementos podem ser identificados na seguinte frase: "Neste contexto, para ser democrática, a escola tem de ser igualmente acessível a todos, diversa no tratamento a cada um e unitária nos resultados" (p.13). Esta questão da uniformidade dos resultados demonstra o caráter técnico da proposta, pois considerando este discurso e a forma como a organização escolar voltou-se para seu desenvolvimento, identificamos a visão da unidade como algo a ser alcançado e controlado pela política dos índices e bônus. Além disso, a uniformidade pauta-se em um ideal inconsistente dentro do próprio marco do documento, uma vez que visa resultados unitários, mas desconsidera as diferentes experiências e interesses culturais dos alunos apontados pelo documento como existentes e que seriam provenientes de diferentes grupos sociais. É reconhecida a existência de aspectos que mediam o processo de ensino aprendizagem, mas é desconsiderada uma reflexão sobre as barreiras que podem inviabilizar que todos obtenham o mesmo domínio de conhecimentos.

d) Prioridade pela competência da leitura e da escrita: considera-se a importância desta para a comunicação do sujeito em sociedade e mesmo em todas as disciplinas e séries, cabendo a todos os professores desenvolvê-la. O texto (escrito ou falado) tem centralidade no processo de ensino e aprendizagem. Este é o princípio cujos pressupostos recebem maior delineamento e esclarecimento, discutindo-se o âmbito da linguagem, dos tipos de textos, da importância do fazer comunicativo sustentado nas competências e habilidades leitoras e de escrita. Há centralidade na linguagem e na capacidade de conseguir compreendê-la e utilizá-la de forma adequada (SÃO PAULO, 2010).

O aprender a ler e a escrever é uma condição básica para a educação escolar, ainda mais se considerarmos a nossa sociedade como a sociedade da informação/conhecimento, como se apresenta no documento do currículo. Além disso, este princípio responsabiliza to- 
dos os professores pelo trabalho que busca superar um dos problemas da educação básica que é o analfabetismo funcional, e para permitir aos alunos a apropriação das diferentes linguagens características das disciplinas escolares.

Entendemos que este princípio tem relação com o Programa Ler e Escrever, voltado para o I Ciclo do Ensino Fundamental do estado de São Paulo, que visa a que todas as crianças com até oito anos de idade sejam alfabetizadas, bem como a garantir a recuperação daqueles que não atingiram esse desenvolvimento ${ }^{3}$. De acordo com o IBGE ${ }^{4}$, no ano de 2011 o estado de São Paulo tinha 0,8\% de analfabetos na idade entre 10 a 14 anos, e 3,7\% de analfabetos na idade de 15 ou mais. Há políticas públicas propostas para se atingir o analfabetismo zero, como é o caso de um projeto voltado para as prefeituras, denominado "Compromisso: São Paulo, Analfabetismo Zero", o qual é vinculado ao programa de nível federal "Brasil Alfabetizado", representado pelo MEC e apoiado pela UNESCO e por outras instituições em nível estadual e municipal.

e) Articulação das Competências para aprender: enfatiza o desenvolvimento da competência do aluno para aprender, considerando como principal foco a atuação do professor; uma vez que vivemos em uma sociedade da informação, que se apresenta em transformação contínua, a escola deve preparar o aluno para esta vida que dele exige um aprendizado constante. Enfatiza, ainda, mesmo havendo esta centralidade no aprender, que não se desconsidera a importância dos conteúdos do ensino. As competências para aprender estão referenciadas entre aquelas do Exame Nacional do Ensino Médio, como desdobramento das competências: leitora e escritora. (SÃO PAULO, 2010).

Vasconcelos (2001), assim como outros autores, realiza críticas ao que considera já ter se tornado um chavão: o princípio do aprender a aprender do aluno. Segundo este autor, de alguma maneira esta afirmação promove sentidos que desvalorizam os conhecimentos, desvalorizam a história, pois permite a interpretação de que o importante não é o saber, mas as formas de procurá-lo quando necessário. No entanto, neste formato de ensino e aprendizagem, ao se considerar a lógica dominante certas necessidades humanas sequer se manifestam. Além disso, localizando esta questão na historicidade da educação, parece que estamos jogando fora o legado do passado que permitiu-nos entender como a educação pode ser instrumento de reprodução social, a partir das teorias reprodutivistas com as quais houve intensa preocupação com relação às ideologias dos conteúdos; no entanto, agora se diz que o aluno pode encontrar informação em qualquer lugar, bastando que aprenda a buscá-la e selecioná-la.

Coloca-se, portanto, um elemento dificultador para o professor, pois este terá que voltar o foco de suas ações para aquilo que permita aos alunos aprenderem a aprender, mas, ao mesmo tempo preencher de conteúdos esse processo. Este princípio traz conflitos entre o conteúdo, a forma e as finalidades do ensino, desconsiderando o compromisso político necessário para o professor.

\footnotetext{
${ }^{3}$ Programa Ler e Escrever: http://lereescrever.fde.sp.gov.br/SysPublic/InternaPrograma.aspx?alkfjlklkjaslkA=260\&ma nudjsns $=0$

${ }^{4}$ De acordo com o site do governo federal Todos pela Educação: http://www.todospelaeducacao.org.br/educacao-nobrasil/numeros-do-brasil/dados-por-estado/sao-paulo/
} 
f) Articulação com o mundo do trabalho: vinculado aos dispositivos da LDB, DCNs e PCNs, esta articulação especifica: a compreensão dos significados das ciências, das letras e das artes; a relação entre teoria e prática em cada disciplina do currículo; as relações entre Educação e Tecnologia; a prioridade para o contexto do trabalho; o contexto do trabalho no Ensino Médio (SÃO PAULO, 2010).

Por fim, outro ponto a ser destacado sobre a apresentação do currículo - em que são trazidos seus principais fundamentos (SÃO PAULO, 2010) - e que dificulta a compreensão dos elementos apresentados, é a total ausência de referências bibliográficas que, eventualmente, indicassem caminhos que permitissem uma compreensão mais aprofundada dos pontos destacados como seus princípios. Diluem-se as disputas existentes entre as diferentes compreensões teóricas em educação, ao se simplificar as discordâncias teóricas sobre as estratégias de organização da prática pedagógica, caracterizando um "modelo" a ser seguido e posto em prática a partir da mudança de foco com relação a alguns aspectos, como se naturalmente disto pudesse decorrer uma reorganização de outros aspectos, como se tudo fosse simples e restrito ao âmbito da alteração de ideias e posicionamentos de professores, gestores e alunos.

Talvez esta indefinição observada e a falta de referenciais que fundamentem o debate do currículo confluam para o que Sacristán (2000) denominou "discurso dominante da pedagogia moderna", caracterizado pelo individualismo sustentado pelo predomínio da abordagem psicológica dos problemas pedagógicos, a qual ressalta o desenvolvimento humano e renega as discussões sobre a função cultural da escola ao se falar do currículo. Esta forma de discurso mascara o significado do ensino, estabelecendo-se assim os fins educativos como algo dado - para o qual é preciso se instrumentalizar e não para ser discutido o que é coerente com os interesses dominantes que se encontram em qualquer projeto educativo.

Para esclarecer melhor este aspecto, cabe citarmos como exemplo a proposta de passar a organizar a prática pedagógica a partir de habilidades e competências a serem desenvolvidas (foco no aluno), e não mais dos conhecimentos a serem ensinados (foco no professor); ainda, em um trecho do documento no qual é feita uma referência ao currículo como espaço de cultura, também está expressa essa simplificação, e uma visão idealista sobre a mudança pedagógica, uma vez que a realidade da escola e a cultura escolar (em especial aquela dos professores) são desconsideradas, indicando que as transformações epistemológicas e metodológicas derivariam da mudança do foco do projeto pedagógico da escola, como se pode deduzir do trecho apresentado a seguir:

Quando, no projeto pedagógico da escola, a cidadania cultural é uma das suas prioridades, o currículo é a referência para ampliar, localizar e contextualizar os conhecimentos acumulados pela humanidade ao longo do tempo. Então, o fato de uma informação ou de um conhecimento emergir de um ou mais contextos distintos na grande rede de informação não será obstáculo à prática cultural resultante da mobilização desses "saberes" nas ciências, artes e nas humanidades (SÃO PAULO, 2011, p.12, grifo nosso).

Esta caracterização idealista de propostas de mudança pedagógica indica uma visão da 
escola que contextualiza o conhecimento em uma sociedade dada pela "grande rede de informações" e não em uma sociedade materializada, capitalista, cheia de disputas, desigualdades, conflitos e contradições. Tal perspectiva é coerente com as teorias educacionais não críticas, pois, como afirma Saviani (1981), estas desconhecem as determinações objetivas e materiais em torno da escola, enquanto espaço de reprodução ideológica e de dominação de uma classe em relação à outra no sentido de desempenhar um papel que garanta e reproduza os interesses da burguesia. Dessa forma, as teorias não críticas são "ideológicas, isto é, dissimulam, para reproduzi-las, as condições de marginalidade em que vivem as camadas trabalhadoras" (p. 23).

\section{CONSIDERAÇÕES FINAIS}

Nossa análise se preocupou, sobretudo, na identificação da concepção políticopedagógica que orientava a política curricular sistematizada em São Paulo (2010), buscando identificar qual(is) ideia(s) pedagógica(s) sustenta $(\mathrm{m})$ ou perpassa $(\mathrm{m})$ o documento que orientava a organização da política educacional do estado e identificar contradições em relação a educação ambiental crítica, a luz da pedagogia histórico-critica.

Como foi possível perceber, o documento do currículo (SÃO PAULO, 2010) está articulado, à sua maneira, à política curricular no nível federal (LDB/96, DCN, PCN, ENEM), buscando realizar uma proposição que contemple o que é entendido necessário para os alunos da Educação Básica, a partir de um referencial do que seja a nossa sociedade atual (sociedade do conhecimento)e com um discurso bastante prescritivo e que coloca barreira para o desenvolvimento de uma concepção crítica sobre a natureza da educação escolar, o que é fundamental para a inserção da educação ambiental enquanto conteúdo essencial dos currículos.

Por fim, poderíamos questionar, o que uma análise buscando identificar as ideias pedagógicas do documento pode nos falar sobre a inserção ou não da educação ambiental crítica no currículo escolar. Como trazido anteriormente, a macrotendência da educação ambiental crítica tem como elemento fundante uma visão de crítica à sociedade capitalista, visando promover uma compreensão de sua constituição histórica e contraditória para sua superação. Portanto, ao falarmos de educação ambiental crítica, não só estamos falando de temáticas ambientais presentes/citadas nos currículos oficiais. Precisamos nos ater a concepção de conhecimento, da relação escola e sociedade, assim como sobre os tipos de mediações são estimuladas e a forma com são vistos e inseridos educandos e educadores nesta prática social. Ademais localizar a própria história de construção da educação pública, das políticas educacionais.

Em contradição a concepção de educação ambiental crítica, no documento extraiu-se que a sociedade é entendida como uma sociedade dinâmica, em constante transformação, caracterizada pela rápida transmissão das informações e seu intenso uso no cotidiano. Também que a educação escolar precisa formar os sujeitos para que estes se integrem a esta sociedade e saibam lidar com as diferenças. Em suma, a partir da análise apresentada identificamos que a teoria educacional que sustenta o currículo oficial é um misto das teo- 
rias não críticas do neoconstrutivismo e neotecnicismo - principalmente centrando-se na pedagogia de competências e habilidades, no aprender a aprender, no desenvolvimento das competências de leitura e escrita, na formação dos sujeitos para a cidadania, na relação educação básica e educação profissional (reafirmando a ideia de que o educando deve ser formado para ser capaz de ter flexibilidade e se adaptar a novas condições de ocupação) e na relação dos conhecimentos curriculares com o cotidiano em nível imediato.

\section{REFERENCIAIS}

APPLE, M. W. A política do conhecimento oficial: faz sentido a ideia de um currículo nacional? Em: MOREIRA, A.F.; SILVA, T. T. Currículo, Cultura e Sociedade. 3a ed. São Paulo: Cortez, 1999.

APPLE, M. W. Ideologia e Currículo. São Paulo: Brasiliense, 1982.

ARCAS, P. H. Saresp e progressão continuada: implicações na avaliação escolar. Estudos em Avaliação Educacional, São Paulo, v. 21, n. 47, p. 473-488, set./dez. 2010

CONTRERAS, J. A autonomia de professores. 2 ed. São Paulo: Cortez, 2012

CURY, C. R. J. Educação e Contradição: elementos metodológicos para uma teoria crítica do fenômeno educativo 7ed. São Paulo: Cortez, 2000.

DUARTE, N. Pela Superação do Esfacelamento do Currículo Realizado pelas Pedagogias Relativistas. Julho/2008b. Disponível em: <http://www.nre.seed.pr.gov.br/cianorte/arqui vos/File/PEDAGOGAS/CURRICULO/PELASUPERACODOESFACELAMENTODOCURRICULOREA LIZADOPELASPEDAGOGIASRELATIVISTASNewtonDuarte.pdf >. Acesso em 4 de fev. de 2014.

DUARTE, N. Sociedade do Conhecimento ou Sociedade das Ilusões. 1a ed. Campinas: Autores Associados, 2008a.

DURAN, M. C. G. A Cenp e as Propostas Curriculares para a Rede Pública De Ensino do Estado de São Paulo. XVI ENDIPE - Encontro Nacional de Didática e Práticas de Ensino. Anais. UNICAMP - Campinas - 2012. P. 14-25. Junqueira \& Marin Editores. Livro 2 - p.002076 $\mathrm{FACCl}, \mathrm{M.G}$. D. Valorização ou esvaziamento do trabalho do professor? Um estudo críticocomparativo da teoria do professor reflexivo, do construtivismo e da psicologia vigotskiana. Campinas: Autores associados, 2004

LAYRARGUES, P. P. Para onde vai a educação ambiental? O cenário político-ideológico da educação ambiental brasileira e os desafios de uma agenda política crítica contrahegemônica. Revista Contemporânea de Educação, no 14, p. 398-421, agosto/dezembro de 2012.

LAYRARGUES, P. P.; LIMA, G. F. da C. Mapeando as macrotendências político-pedagógicas da educação ambiental contemporânea no Brasil. Em: VI Encontro "Pesquisa em Educação Ambiental”, Ribeirão Preto, 2011, Anais..., p.1-15, 2011, CD-ROM.

OKUBO, T. C. de A. Q. Currículo em contextos: permeabilidades discursivas na proposta curricular do estado de São Paulo (2008). 2012. 154 p. Tese (doutorado) - Universidade Estadual de Campinas, Faculdade de Educação, Campinas, SP. Disponível em: http://www. bibliotecadigital.unicamp.br/document/?code=000878015>. Acesso em: 28 de abr. de 
2013.

PALMA FILHO, J. C. A política educacional do Estado de São Paulo (1983-2008). Educação \& Linguagem, v. 13, $\mathrm{n}^{\circ} 21,2010$

RIBEIRO, R. A autonomia proposta na LDBEN e a nova proposta curricular das escolas públicas estaduais de São Paulo. Revista IberoAmericana de Estudos em Educação, v. 3, p. 1 e 2, 2008.

SACRISTÁN, J. G. O currículo: uma reflexão sobre a prática. 3. ed. Porto Alegre: ArtMed, 2000

SANTOS, R. dos; FRENEDOZO, R. de C.. Educação ambiental no ensino de biologia do currículo oficial da Secretaria da Educação do Estado de São Paulo. Revista Eletrônica do Mestrado de Educação Ambiental. 256, v. 30, n.2, p. 107-126,jul./dez. 2013.

SÃO PAULO, Secretaria da Educação. Currículo do Estado de São Paulo: Ciências da Natureza e suas tecnologias. São Paulo: SEE, 2010.

SAVIANI, D. Escola e Democracia. 4a ed, Campinas: Editores Associados; Editora Cortez, 1981.

SAVIANI, D. História das Ideias Pedagógicas no Brasil. 3a ed. Campinas: Autores Associados, 2010.

SAVIANI, D. Pedagogia Histórico-crítica. Primeiras aproximações. 11 o ed. Campinas: Editores associados, 2011.

SILVA, T. T. da.Documentos de Identidade: Uma Introdução às Teorias de Currículo. $3^{\circ}$ Edição. Editora Autêntica. 2010.

SOUZA, D. C. DE. A educação ambiental crítica e sua construção na escola pública: compreendendo contradições pelos caminhos da formação de professores. 2014, 354f. TESE (Doutorado em Educação para a Ciência). Faculdade de Ciências, UNESP, Bauru, 2014.

SOUZA, D. C.; SALVI, R. F. Cartografia da pesquisa sobre formação de professores em educação ambiental nas áreas de Educação e de Ensino de Ciências e Matemática. Revista Brasileira de Pesquisa em Educação em Ciências. V. 12, n. 2, 2012.

TOZONI-REIS et ali. Conteúdos curriculares da educação ambiental na escola:

contribuições da pedagogia histórico-crítica. Em: VII Encontro de Pesquisa em Educação Ambiental, EPEA, 2013, Rio Claro - SP. Anais.. 2013. Disponível em: <http://www.epea. tmp.br/epea2013_anais/pdfs/plenary/0190-1.pdf>. Acesso em: 04 de fev. de 2014.

TOZONI-REIS, M. F. de C. (Re)Pensando a Educação Ambiental. In: Metodologias Aplicadas à Educação Ambiental. São Paulo: IESDE, 2006 a.

VASCONCELLOS, C. dos S. Para onde vai o professor? Resgate do professor como sujeito de transformação. 8a ed. São Paulo: Libertad, 2001.

VEIGA, A.; AMORIM, É.; BLANCO, M. Um Retrato da Presença da Educação Ambiental no Ensino Fundamental Brasileiro: o percurso de um processo acelerado de expansão. Brasília: Instituto Nacional de Estudos e Pesquisas Educacionais Anísio Teixeira, 2005. 